\title{
Evaluation of nebulised acetylcysteine and normal saline in the treatment of sputum retention following thoracotomy
}

\author{
Alison M Gallon
}

\begin{abstract}
Background - The use of acetylcysteine as a mucolytic agent is controversial. In 1962 it was claimed to be "the most effective agent ... for the liquefaction of ... secretions" but was subsequently taken off the market as a respirator solution. Normal saline, on the other hand, is becoming increasingly popular. A study was undertaken to determine which solution is more effective at clearing retained secretions following thoracotomy.

Methods-The study included 10 patients and was of single blind, two-way crossover design. Measurements taken before and after each treatment included sputum viscosity, difficulty of expectoration, weight of sputum expectorated, and oxygen saturation.

Results - Following nebulisation of acetylcysteine, sputum viscosity was reduced, difficulty of expectoration was reduced, the weight of sputum expectorated was increased, and oxygen saturation was increased. There were no changes after nebulisation of normal saline.

Conclusions-This study shows that, following thoracotomy, nebulised acetylcysteine reduces sputum viscosity, making expectoration easier and improving oxygenation. Nebulised normal saline has no effect.

(Thorax 1996;51:429-432)
\end{abstract}

Keywords: nebulised acetylcysteine, sputum viscosity, physiotherapy

Postoperative pulmonary complications following abdominal and thoracic surgery are the most significant cause of morbidity and mortality in the postoperative period. ${ }^{1}$ Thoracotomy results in reduced lung volumes, impaired gas exchange, and damaged respiratory defence mechanisms. ${ }^{2}$ Mucus secretion and viscosity are therefore increased and mucociliary clearance is decreased, leading to retention of secretions, atelectasis, infection, and hypoxaemia. ${ }^{34}$

The use of nebulised mycolytic agents is one method of enhancing mucociliary clearance. Acetylcysteine has been shown to reduce mucus viscosity in vitro ${ }^{5}$ but this has not been demonstrated in vivo in the postoperative period. Nebulised normal saline has been shown to increase the clearance of secretions when included in a physiotherapy regimen for the treatment of patients with bronchiectasis. ${ }^{6}$ No studies of nebulised drugs have measured spu- tum viscosity in patients following thoracotomy. A controlled trial was therefore undertaken to compare the efficacy of nebulised acetylcysteine and normal saline in the treatment of sputum retention following thoracotomy in order to establish which is the more effective drug at increasing mucociliary clearance and facilitating cough.

\section{Methods}

PATIENTS

Eleven patients (10 men) aged 36-77 years (mean 64.7) took part in the study. All patients undergoing thoracotomy were assessed by the author and recruited if they met the following entry criteria: (1) difficulty expectorating tenacious secretions, and (2) adequate analgesia to enable effective coughing.

Patients were excluded if they had a recurrent laryngeal nerve palsy. Withdrawal criteria included (1) severe bronchospasm, (2) pulmonary oedema, (3) adult respiratory distress syndrome, (4) surgical emphysema, or (5) serious cardiac complications.

The study was approved by the district ethics committee and all patients were given a full written and verbal explanation of the study.

\section{STUDY DESIGN}

The study was of a single blind, two-way crossover design comparing nebulised acetylcysteine with nebulised normal saline. Patients received treatments 1 and 2 four hours apart. The order of treatments was randomly allocated (using a random numbers table and random permuted blocks) and was reversed on day 2 (treatments 3 and 4). The patients were not aware of which drug they were receiving.

Forty minutes before treatment any sputum expectorated was collected. During this period deep breathing exercises and assisted coughing were encouraged at 10 minute intervals. This comprised six thoracic expansion exercises, huffing, and manual support of the wound.

A fresh sputum pot was supplied and the first treatment commenced. Treatment A comprised $4 \mathrm{ml}$ nebulised acetylcysteine (20\%), deep breathing exercises, and assisted coughing. Treatment $\mathrm{B}$ comprised $4 \mathrm{ml}$ nebulised normal saline $(0.9 \%)$, deep breathing exercises, and assisted coughing. Each drug was nebulised using a Medic-Aid Acorn nebuliser, delivering particles of less than $5 \mu \mathrm{m}$, driven by a Medix AC 2000 compressor at a flow rate of $6.5 \mathrm{l} /$ min. Most of the drug was nebulised within 


\begin{tabular}{|c|c|c|c|c|c|}
\hline $\begin{array}{l}\text { Patient } \\
\text { no. }\end{array}$ & Sex & Age & Operation & Incision & $\begin{array}{l}\text { Length of } \\
\text { anaesthesia } \\
\text { (hours) }\end{array}$ \\
\hline 1 & $M$ & 70 & Decortication & $\mathrm{R}$ thoracotomy & $2 \cdot 5$ \\
\hline 2 & $M$ & 63 & $\begin{array}{l}\text { Hiatal hernia } \\
\text { repair }\end{array}$ & L thoracotomy & 3 \\
\hline 3 & $M$ & 69 & Lower lobectomy & $\mathrm{R}$ thoracotomy & $2 \cdot 75$ \\
\hline 4 & M & 73 & Upper lobectomy & $\mathrm{L}$ thoracotomy & 3 \\
\hline 5 & $\mathrm{~F}$ & 36 & Oesophagectomy & $\mathrm{L}$ thoracoabdominal & 4 \\
\hline 6 & $M$ & 69 & Bullectomy & $\mathrm{L}$ thoracotomy & $1 \cdot 5$ \\
\hline 7 & $M$ & 77 & Oesophagectomy & $\begin{array}{l}\text { Laparotomy and } \\
\mathrm{R} \text { thoracotomy }\end{array}$ & $4 \cdot 25$ \\
\hline 8 & $M$ & 67 & Oesophagectomy & $\begin{array}{l}\text { Laparotomy and } \\
\mathrm{R} \text { thoracotomy }\end{array}$ & 5 \\
\hline 9 & $M$ & 49 & Decortication & $\mathrm{L}$ thoracotomy & 2 \\
\hline 10 & $M$ & 74 & Oesophagectomy & $\begin{array}{l}\text { Laparotomy and } \\
\mathrm{R} \text { thoracotomy }\end{array}$ & $5 \cdot 25$ \\
\hline
\end{tabular}

10 minutes. The nebulisers were driven by compressed air because oxygen inactivates acetylcysteine. ${ }^{7}$ A fresh nebuliser was used for each treatment and face masks were used with the nebulisers for better patient compliance. ${ }^{8}$ The drugs were administered with the patient sitting upright, either in bed or in a chair. The deep breathing exercises and assisted coughing were repeated at 10 minute intervals as before. After 40 minutes - that is, 10 minutes of nebulised drug plus 30 minutes of intermittent deep breathing exercises and assisted coughing treatment was discontinued. Treatment 2 was commenced four hours after the start of treatment 1 . Treatments 3 and 4 were administered the next day, again four hours apart.

No other nebulised drugs were given during the study period. Analgesia was given by bolus doses of epidural methadone. The study was conducted on either the first and second or the second and third postoperative days.

\section{MEASUREMENTS}

Sputum expectorated 40 minutes before treatment and during the 40 minute treatment period was weighed using Pitney Bowes electronic scales. The viscosity of sputum expectorated before and after treatment was measured using a parallel plate rheometer (Instron 3250).

Each patient was asked to complete a visual analogue scale to measure the degree of difficulty of expectoration before and after treatment.

Oxygen saturation $\left(\mathrm{SaO}_{2}\right)$ was measured with a pulse oximeter (Life Stat 1600 Physio Control) before and after treatment. Three readings were taken on each occasion at one minute intervals.

\section{DATA ANALYSIS}

The $t$ test for paired samples was used to analyse all the data which showed a normal distribution (weight of sputum, difficulty of expectoration, and oxygen saturation). Data on sputum viscosity were analysed using the Wilcoxon matched pairs (signed rank) test because the trial was small and the viscosity measurements had a skewed distribution.

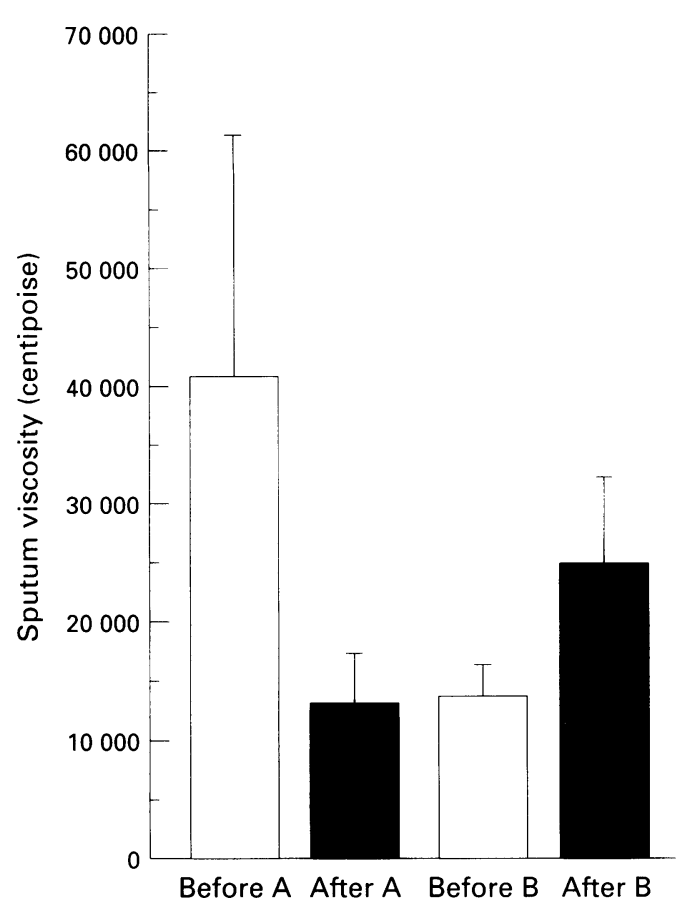

Mean (SE) sputum viscosity before and after treatments $A$ ( $4 \mathrm{ml}$ nebulised acetylcysteine) and $B(4 \mathrm{ml}$ nebulised saline).

\section{Results}

Eleven patients were recruited but one was withdrawn after he developed severe pulmonary oedema. The characteristics of the remaining 10 patients are shown in the table.

\section{SPUTUM VISCOSITY}

Sputum viscosity was reduced by acetylcysteine but not by normal saline. The mean (SD) viscosity of sputum before treatment $A$ was 40635 (76418) centipoise (cP) (range 4849-297 100) and after treatment was 13160 (14970) cP (range 2294-49070). This reduction was statistically significant $(\mathrm{p}=0 \cdot 001)$. Before treatment $B$ the mean (SD) viscosity of the sputum was 13437 (10634) cP (range 5180-38500) and after treatment was 24735 (27 714) cP (range 4244-95360). This increase was not statistically significant (figure).

\section{WEIGHT OF SPUTUM EXPECTORATED}

There was an increase in the weight of sputum expectorated after acetylcysteine but not after normal saline. The mean (SD) weight of sputum expectorated before treatment A was $2 \cdot 65$ (3.47) $\mathrm{g}$ (range 0-15) and after treatment was $7 \cdot 5(6 \cdot 29) \mathrm{g}$ (range $0-26)$. This increase was statistically significant $(p<0 \cdot 0001)$. Before treatment $B$ the mean (SD) weight of sputum expectorated was $3 \cdot 45(2 \cdot 16) \mathrm{g}$ (range $0-7)$ and after treatment was $3.55(2.99) \mathrm{g}$ (range 0-11). This was not statistically significant.

\section{DIFFICULTY OF EXPECTORATION}

Expectoration of sputum was easier after acetylcysteine but not after normal saline. Difficulty of expectoration was measured using 
a $10 \mathrm{~cm}$ visual analogue scale. The mean (SD) score before treatment $A$ was 7.57 (2.02) (range $3 \cdot 45-9 \cdot 8)$ and after treatment was $3 \cdot 82(2 \cdot 11)$ (range 1.3-9.8); $\mathrm{p}<0.0001$. Before treatment $\mathrm{B}$ the mean (SD) score was $6 \cdot 16(2 \cdot 26)$ (range 2.2-9.65) and after treatment was $5.89(2.57)$ (range $1 \cdot 8-9 \cdot 9) ; \mathrm{p}=\mathrm{NS}$.

\section{OXYGEN SATURATION}

Oxygen saturation improved after acetylcysteine but not after normal saline. The mean (SD) oxygen saturation before treatment $\mathrm{A}$ was $91.6(3.75) \%$ (range $87-99.3 \%$ ) and after treatment was $93.96(2.67) \%$ (range 89.6 $100 \%), p<0.0001$. Before treatment $\mathrm{B}$ the mean (SD) $\mathrm{SaO}_{2}$ was 93.08 (3.23)\% (range $88-98 \cdot 3 \%)$ and after treatment was 93.35 $(3 \cdot 64) \%$ (range $87 \cdot 6-100 \%$ ), $\mathrm{p}=\mathrm{NS}$.

\section{Discussion}

The distinctive sulphurous odour of acetylcysteine precluded a double blind study. The same volumes of normal saline and acetylcysteine were required to allow for the effect of humidification from inhaling a nebulised mist. The crossover design was used because within patient studies allow a more precise comparison of treatments. Patients vary greatly in their disease state and response to treatment and substantial numbers would be needed to achieve useful results in between patient studies.

In this study the sputum viscosity varied considerably both before and after treatment, but it was the change following treatment in any one individual that was important. The difference in sputum viscosity before treatments A and B was not statistically significant.

The reversal of treatment order on the second day served to avoid any diurnal variation in sputum rheology or the quantity produced, and to eliminate any possibility of carryover effect. The half life of nebulised acetylcysteine has not been calculated, but that of the intravenously administered drug is 1.95 and 5.58 hours for reduced and total acetylcysteine, respectively. ${ }^{9}$

A reduction in sputum viscosity might have been produced with time, by the reduced effect of anaesthetic agents, and the state of the patient's hydration. This was not the case as an increase in viscosity was found in some patients after normal saline. Similarly, expectoration might become easier with time but this did not occur following normal saline.

Using the radioaerosol labelling technique to measure mucociliary clearance would have given a more accurate picture of the volume of sputum clearance and the areas of lung from which it was being cleared. This technique was not possible after thoracotomy, however, and several studies have used both radioaerosol clearance and weight of sputum expectorated with good correlation. ${ }^{610-12}$

The findings of this study are in agreement with those of other workers in which nebulised acetylcysteine has been used in patients with various respiratory diseases or following nonpulmonary surgery. Reduced sputum vis- cosity, ${ }^{13-15}$ increased sputum volume, ${ }^{1314}$ and reduced atelectasis ${ }^{16}$ have all been reported following treatment with nebulised acetylcysteine.

In 1970 Giordano et al ${ }^{17}$ measured mucociliary clearance in vivo in anaesthetised dogs by a radioisotopic method and found it to be significantly increased $(p<0.001)$ following nebulisation of a $20 \%$ solution of acetylcysteine. These workers hypothesised that, because of its supposed irritant effect, acetylcysteine might cause a reflex hypersecretion of mucus. This would enable a patient to mobilise his tracheobronchial secretions more effectively, which might be interpreted as an increased mucus transport rate. However, Medici and Chodosh $^{18}$ have shown that inhalation of a $10 \%$ solution of acetylcysteine in humans results in an initial decrease in viscosity with no change or a reduction in sputum volume.

Studies using systemic acetylcysteine have shown conflicting results on clinical and physiological measurements, with some showing a benefit ${ }^{19-22}$ while others have shown no effect. $^{23-26}$

I would like to thank Mr Barry Ross and Mr Roger Vaughan for allowing me to study their patients. I am very grateful to Dr Chris Dawson, Dr Geoff Brownsey and Mike Ridout for their help with the viscosity measurements, to Dr Sandra Rainbow for her help with the statistical analysis, and to Rick Adams for his pharmacological advice. My thanks also go to Andrea Hindell and Nicola Clemence for their support, and to Dr Brian Harrison and $\mathrm{Mr}$ Barry Ross for reviewing the manuscript.

1 Bartlett RH, Gazzaniga AB, Geraghty TR. Respiratory manoeuvres to prevent postoperative pulmonary complications. $\mathcal{F A M A}$ 1973;224:1017-21.

2 Benumof JL. Anaesthesia for thoracic surgery. Philadelphia: WB Saunders, 1987.

3 Fairshter RD, Williams JH Jnr. Pulmonary physiology in the postoperative period. Crit Care Clin 1987;3:287-306.

4 Gamsu G, Singer MM, Vincent HH, Berry S, Nadel JA. Postoperative impairment of mucus transport. Am Rev Respir Dis 1976;114:673-9.

5 Sheffner AL, Medler EM, Jacobs LW, Sarett HP. The in vitro reduction in viscosity of human tracheobronchial secretions by acetylcysteine. Am Rev Respir Dis 1964;90: $721-9$.

6 Sutton PP, Gemmell HG, Innes N, Davidson J, Smith FW, Legge JS, et al. Use of nebulised saline and nebulised terbutaline as an adjunct to chest physiotherapy. Thorax 1988;43:57-60.

7 Lawson D, Saggers BA. NAC and antibiotics in cystic fibrosis. BMF $1965 ; 317$.

8 Steventon RD, Wilson RSE. Facemask or mouthpiece for delivery of nebulised bronchodilator aerosols? $\mathrm{Br} \mathcal{F}$ Dis Chest 1981;75:88-90.

9 Olsson B. Pharmacokinetics and bioavailability of reduced and oxidised N-acetylcysteine. Eur f Clin Pharmacol 1988; 34:77-82.

10 Sutton PP, Lopez-Vidriero MT, Pavia D, Newman SP, Clay MM, Webber BA, et al. Assessment of percussion, viay MM, Webber BA, et al. Assessment of percussion, vibratory-shaking and breathing exercises in
therapy. Eur $\mathcal{F}$ Respir Dis $1985 ; 66: 147-152$.

11 Conway JH, Fleming JS, Perring S, Holgate ST. Humidification as an adjunct to chest physiotherapy in aiding tracheobronchial clearance in patients with bronchiectasis. Respir Med 1992;86:109-14.

2 Thomson ML, Pavia D, Jones CJ, McQuiston TAC. No demonstrable effect of $S$-carboxymethylcysteine on clearance of secretions from the human lung. Thorax $1981 ; 36$ : $891-5$

13 Webb WR. Clinical evaluation of a new mucolytic agent, acetylcysteine. F Thorac Cardiovasc Surg, 1962;44:330-43.

14 Hurst GA, Shaw PB, LeMaistre CA. Laboratory and clinical evaluation of the mucolytic properties of acetylcysteine. evaluation of the mucolytic properties
Am Rev Respir Dis 1967;96:962-70.

15 Reas HW. The effect of N-acetylcysteine on the viscosity of tracheobronchial secretions in cystic fibrosis of the
of of tracheobronchial secretions in

16 Thomas PA, Lynch RE, Merrigan EH. Prevention of postoperative pulmonary atelectasis. Review of 215 cases and evaluation of acetylcysteine. Am Surg 1966;12:301-7.

17 Giordano A, Holsclaw D, Litt M. Effects of various drugs on canine tracheal mucociliary transport. Ann Otol 1978; 87:484-90.

18 Medici TC, Chodosh S. Die abwehrleistungen des Respirationstraktes. Schweiz Med Wochenschr 1975;105:96570 . 
19 Grassi C. Long-term oral acetylcysteine in chronic bronchitis. A double-blind controlled study (multi-centre group). Eur F Respir Dis 1980;61 (Suppl 111):93-108.

20 Boman G, Backer U, Larsson B, Melander B, Wahlander $\mathrm{L}$. Oral acetylcysteine reduces exacerbation rate in chronic bronchitis. Report of a trial organised by the Swedish 64:405-15.

21 MacFarlane JT, Prescott RJ. Oral acetylcysteine exacerbation rates in patients with chronic bronchitis and acerbation rates in patients with chronic bronchitis and severe airways obstruction. BTS Research Committec. Thorax 1985;49:932-5.

22 Todisco T, Polidori R, Rossi F, Iannacci L, Bruni B, Fedel $\mathrm{L}$, et al. Effect of $\mathrm{N}$-acetylcysteine in subjects with slow mucociliary clearance. Eur $\mathcal{f}$ Respir Dis 1985;66 (Suppl 139): 136-41.
23 Jepsen S, Klaerke A, Nielsen PH, Nielsen ST, Simonsen O. Systemic administration of $\mathrm{N}$-acetylcysteine has no effect on postoperative lung function following elective upper laparotomy in lung healthy patients. Acta Anaesupper laparotomy in lung health
thesiol Scand 1989;33:219-22.

24 Marriott C, Turton C, Davis SS. An investigation of the physical biochemical properties of the sputum from chronic bronchitics treated with $\mathrm{N}$-acetylcysteine. Thorax 1984;39:238.

25 Millar AB, Pavia D, Agnew JE, Lopez-Vidriero MT, Laugue D, Clarke SW. Effect of oral N-acetylcysteine on mucus clearance. Br f Dis Chest 1985;79:262-6.

26 Bylin G, Hedenstierna G, Lagerstrand L, Wagner PD. No influence of acetylcysteine on gas exchange and spirometry in chronic asthma. Eur f Respir Dis 1987;71:102-7. 